\title{
ENTRE A INCLUSÃO E A EXCLUSÃO: CAMINHOS DA EDUCAÇÃO DE SURDOS NO BRASIL
}

\author{
BETWEEN INCLUSION AND EXCLUSION: PATHS TO DEAF \\ EDUCATION IN BRAZIL
}

Cleide Emília Faye Pedrosa ${ }^{1}$

\section{Resumo}

Vive-se, na atualidade, em sociedades que enfrentam seus extremos dicotômicos. As relações de poder establecidas nelas fazem suas próprias vitimas de exclusão (ORTÚZAR, 2016). Essas questões são priorizadas por pesquisadores em Análise Crítica do Discurso (ACD) (FAIRCLOUGH, 2008); cujo objetivo princiapal é estudar as práticas sociais a partir da perspectiva dos grupos dominados. Ao assumir essa área, escolhemos a comunidade surda como grupo vulnerável e o objetivo de analisar, linguístico-sociodiscursivamente, fragmentos de documentos que apontam para as reivindicações dos surdos quanto ao seu direito a uma educação bilíngue, a sua cultura e a sua identidade. A metodologia utilizada será aplicada, qualitativa e interpretativista. Os corpora são Lei e Decreto da Libras (2002; 2005); Carta reivindicativa de doutores surdos (2012); depoimento de audiência pública (2019). Os resultados indicaram que os documentos oferecem condições de recuperar a memória discursiva e sociohistórica da comunidade surda e sua luta por uma educação bilingue.

\section{Palavras-Chave}

Análise Crítica do Discurso. Comunidade surda. Documentos. Educação bilíngue.

\begin{abstract}
Today, we live in societies that face their dichotomous extremes. The power relations established in them make their own victims of exclusion (ORTÜZAR, 2016). These issues are prioritized by researchers in Critical Discourse Analysis (CDA) (FAIRCLOUGH, 2008); whose main objective is to study social practices from dominated groups' perspective. For that, we chose the deaf community as a vulnerable group and the objective of analyzing, linguistically and socio-discursively, fragments of documents pointing to the deaf's claims, regarding their right to bilingual education, culture and identity. We applied the methodology in a qualitative and interpretative way. The corpora are: Law No. 10.436, of April 24 ${ }^{\text {th }}$, 2002; Decree No. 5.626, of December 22 ${ }^{\text {nd }}$, 2005; an Open Letter, written by Deaf Ph. Ds (2012); public hearing statement (2019). The results indicated that the documents offer conditions to recover the discursive and socio-historical memory of the deaf community and their struggle for bilingual education.
\end{abstract}

\section{KeYWORDS}

Critical discourse analysis. Deaf community. Documents. Bilingual education.

1 Doutora em Letras pela Universidade Federal de Pernambuco, professora da Universidade Federal de Sergipe. 


\section{INTRODUÇÃo}

Ainda vivemos em sociedades que enfrentam seus extremos dicotômicos, como a brasileira por exemplo. As relações de (abuso de) poder, que nelas se estabelecem, fazem suas próprias vítimas de exclusão (ORTÚZAR, 2016). Enfrentar estas questões, torna-se uma resposta de prática de cidadania para os pesquisadores em Análise Crítica do Discurso - ACD (FAIRCLOUGH, 2008; MAGALHAES, MARTINS, RESENDE, 2017; PEDROSA, 2018).

A ACD apresenta várias correntes em seu paradigma, entre elas, iremos focar na Abordagem Sociológica e Comunicacional do Discurso, abordagem brasileira, que, por sua vez, também estabelece diálogos com alguns campos do saber, como: a Sociologia para a Mudança Social, Comunicação para Mudança Social Estudos e Culturais. Para este texto, o diálogo será, primordialmente, com a Sociologia para a Mudança Social e seu subsídio para os estudos de relações de poder e mudanças sociais.

Assumindo este escopo, elegemos como grupo vulnerável a comunidade surda. Esta escolha é resultado de nossa experiência com turmas universitárias híbridas de surdos e ouvintes como alunos da disciplina Linguística, resultado também de pesquisas desenvolvidas, como orientadora, nos níveis de iniciação cientifica na graduação, mestrado, doutorado e tutora no pós-doutorado. E atualmente com projeto de pós-doutorado, pessoal, em que compararemos as mudanças sociais para surdos no Brasil e em Portugal na Universidade de Lisboa (2019 - 2020).

Para atender o objetivo deste artigo - analisar, linguístico-sociodiscursimente, trechos de documentos que apontam para as reivindicações dos surdos quanto a seu direito por uma educação bilíngue, a configuração do texto seguirá os seguintes tópicos que responderão a proposta em pauta: Análise Crítica do Discurso: a voz das minorias; Estudos Surdos: "polifonía social” entre surdos e ouvintes; Abordagem Sociológica e Comunicacional do Discurso: contribuições para estudos em relações de poder e mudança social; por uma metodologia para a análise sócio discursiva; polarização de vozes: os caminhos para a educação de surdos no Brasil; (In)conclusão.

\section{Análise Crítica do Discurso: a voz das minorias}

Pesquisar com a base teórica-metodológica da Análise Crítica do Discurso (ACD) é buscar dar voz às minorias através do desvelamento de discursos hegemônicos dos detentores de poder, de conhecimento, e da "verdade". E, por sua vez, dar voz às minorias, significa polarizar e expor as vozes dominantes.

Bauman (2009, p.28), com base no pensamento de Cornelius Castoriadis, filósofo, economista e psicanalista francês do século XX, que defendia que o que está mal em nossa sociedade é que deixou de questionar a si mesma, afirma: "se trata de un tipo de socicedad qu ya no reconece la alternativa de outra sociedade, y por lo tanto se considera absuelta del deber de examinar, demonstrar, justificar ly más aun probar) la validez de sus presupuestos explícitos ou implícitos". Diante de uma descrição desta, reforça-se o posicionamento político da ACD: examinar, questionar e explicitar os discursos resultantes de práticas sociais dominantes.

Segundo Van Dijk (2008), quem faz estudos críticos deve ser solidário com os grupos vulneráveis, com os excluídos socialmente porque o analista crítico se inquieta diante de situação desprivilegiada de alguns grupos ou comunidades. Ainda o analista crítico mencionado, chama a 
atenção para o abuso do poder social de grupos e instituições sobre o indivíduo e também sobre o discurso. Essa discussão acerca da relação da ACD com poder e linguagem pode ser vista em outras referências, como em Fairclough (2008), Wodak (1997) e Pedrosa (2008).

Desde final da década de 1980, que a Análise Crítica do Discurso tornou-se um campo estabelecido nas ciências sociais. Para Wodak (2013, p. XX, tradução nossa) ${ }^{2}$, a ACD não seria uma disciplina acadêmica segundo a visão tradicional, "com um conjunto fixo de teorias, categorias, suposições ou métodos de pesquisa". Porém, ela se define como "um programa de pesquisa interdisciplinar orientado a problemas, incluindo uma variedade de abordagens, cada uma baseada em diferentes suposições epistemológicas, com diferentes modelos teóricos, métodos de pesquisa e agenda". Diante desse posicionamento, o que une os pesquisadores dessas diversas abordagens "é um interesse compartilhado pelas dimensões semióticas de poder, injustiça e mudança político-econômica, social ou cultural em nosso mundo e sociedades globalizados e globalizantes". E, embora trabalhemos com aspectos de problemas sociais negativos, sob a perspectiva das minorias, como desde o início anunciou Van Dijk (1993, p. 252, tradução nossa) - a ACD “deveria lidar primeiramente com as dimensões discursivas do abuso de poder e a injustiça e desigualdade que resultam dele", isto, porém, não significa que só trabalhemos sob esta ótica.

Para fazer ACD é vital compreender a natureza do domínio e poder social. É preciso saber que o poder social tem por base o acesso privilegiado, de alguns, a recursos que são socialmente valorizados, para citar uns: riqueza, status, posição, participação em grupos reconhecidos, educação e conhecimento. A partir desta percepção, pode-se estabelecer ideias em como o discurso coopera para a reprodução deste poder (VAN DIJK, 1993, p. 254).

Neste contexto, podemos ver em como os discursos da maioria dos experts ouvintes sobre a educação de surdos, predominaram no cenário nacional e internacional forçando os surdos a serem oralizados e a usarem uma língua que não é/era a sua, nem tampouco que tem acesso naturalmente. Vigora assim, a dicotomia, a binaridade, a polarização entre surdos e ouvintes, entre inclusão e exclusão.

\section{Estudos SuRdos: "POLIFONÍA SOCIAL" ENTRE SURdos E OUVINTES}

Historicamente o povo surdo tem sido vítima de uma sociedade ouvintista. Segundo a professora surda, Karin Strobel, nomeada ${ }^{4}$, em 24 de janeiro de 2019, com posse em 30 de janeiro, diretora de Políticas de Educação Bilíngue de Surdos na Secretaria de Modalidades Especializadas de Educação no âmbito do Ministério de Educação do Brasil (MEC), a história dos surdos foram, quase sempre, apresentada pelo ponto de vista dos ouvintes, havendo, de um modo geral, "esforços de tornar os sujeitos surdos de acordo com os modelos ouvintes oferecendo 'curas' para as suas 'audições' danificadas (STROBEL, 2009, p. 03). Segundo a mesma autora, o melhor lugar para "ouvir" os surdos é em suas Associações.

2 (...) CDA cannot be regarded as a discrete academic discipline in any traditional sense, with a fixed set of theories, categor ies, assumptions or research methods. (...)Instead, CDA can be seen as (...) research programme, subsuming a var iety of approaches, each drawing on different epistemological assumptions, with different theoretical models, research methods and agenda. (....) shared interest in the semiotic dimensions of power, injustice and politicaleconomic, social or cultural change in our globalised and globalising world and societies.

3 CDA should deal primarily with the discourse dimensions of power abuse and the injustice and inequality that result from it. (VAN DIJK, 1993, p. 252)

4 Cf. http://bit.ly/30bbbL4, acesso em 04/06/2019., às 04h55. 
O próprio fato de apenas em 2019 surdos serem nomeados para representar suas políticas educacionais, indica a presença, até então, de ouvintes nas secretarias do MEC. Além da Karin Strobel, foi nomeada a Dra. Flaviane Reis ${ }^{5}$ para o exercício do cargo de Coordenador-Geral da Coordenação-Geral da Política Pedagógica da Educação Bilíngue da Diretoria de Políticas de Educação Bilíngue de Surdos da Secretaria de Modalidades Especializadas de Educação do Ministério de Educação (MEC). Os surdos têm esperanças que, com estas novas políticas do MEC, sua história mude.

Não é sem razão que os surdos aguardam esta mudança, pois, as consequências das decisões do Congresso Internacional de Surdo-Mudez, realizado em Milão em 1880, tem marcado sua história de maneira traumática até os dias atuais. Neste congresso, com grande influência de educadores ouvintistas de diversos países, inclusive com a presença do conhecido Alexander Graham Bell, a pedagogia para ensino dos surdos através da oralismo puro teve vitória esmagadora. Uns dos poucos representantes das línguas de sinais e que foram votos vencidos foram os cinco representantes dos Estados Unidos (STROBEL, 2009).

Do relatório de Kinsey, um representante que exerceu a função de Secretário da parte anglófona ${ }^{6}$ deste Congresso, destacaremos algumas questões discutidas e as decisões tomadas com ênfase nos métodos a serem utilizados na educação de surdos:

Em métodos. 1. Declare as vantagens do Método de Articulação sobre o dos Signos, e vice-versa (olhando para ele principalmente do ponto de vista do desenvolvimento mental sem ignorar sua relação do ponto de vista social). 2. Explique em que consiste o método "Pure Oral", e mostre a diferença entre isso e o sistema "Combinado". 3. Defina exatamente o limite entre os chamados sinais "Metódicos" e os chamados "Naturais". 4. Quais são os meios mais naturais e eficazes pelos quais o surdo-mudo facilmente adquirirá o uso de sua própria língua? (KINSEY, 1880, p. 3-4, tradução nossa). ${ }^{7}$

Estes tópicos (e outros) foram discutidos fortemente e, como resultado, tiveram as seguintes resoluções:

I - O Congresso - Considerando a incontestável superioridade da fala sobre os sinais, restaurando o surdo-mudo para a sociedade e dando-lhe um perfeito conhecimento da lingua, declara que o método oralista deve ser preferido ao dos sinais para a educação e a instrução dos surdos e mudos. II - O Congresso - Considerando que o uso simultâneo de fala e sinais tem a desvantagem de prejudicar a fala, a leitura labial e a precisão de idéias, declara que o método oralista puro deveria ser preferido (...). IV - O Congresso Considerando que o ensino do surdo pelo método oralista puro deve assemelhar-se tanto quanto possível àqueles que ouvem e falam, declara 1. Que o meio mais natural e eficaz pelo qual o surdo-falante pode adquirir o conhecimento da língua é o método "intuitivo",

5 Cf. http://bit.ly/2RdfEsz. Portaria no 269, de 4 de fevereiro de 2019, do Diário da União, Publicado em: 05/02/2019, Edição: 25, Seção: 2, Página: 20 Órgão: Ministério da Educação/Gabinete do Ministro.

6 Rochelle, 1880, faz o relato em francês.

7 On methods. 1. State the advantages of the Articulation Method over that of Signs, and vice versa (looking at it chiefly from the point of mental development without ignor ing its relation in a social point of view). 2. Explain in what the "Pure Oral" method consists, and show the difference between that and the "Combined" system. 3. Define exactly the boundary between so-called "Methodical" signs and those called "Natural". 4. What are the most natural and effectual means by which the Deaf-Mute will readily acquire the use of his own language? 
isto é, aquilo que consiste em expor, primeiro pela fala, e depois pela escrita, os objetos e os fatos que são colocados diante dos olhos dos alunos (....). ${ }^{8}$

É bom reforçar este contexto com as palavras de Sá:

\begin{abstract}
Em síntese, a história dos surdos, contada pelos não-surdos, é mais ou menos assim: primeiramente os surdos foram "descobertos" pelos ouvintes, depois eles foram isolados da sociedade para serem "educados" e afinal conseguirem ser como os ouvintes (SÁ, 2019, p. 03). ${ }^{9}$
\end{abstract}

Este foi o grande lema do congresso mencionado: "normalizar" os surdos, “ajudá-los" a se tornar ouvintes. Foi necessária uma longa jornada para os surdos se reunirem em comunidades e fundarem associações.

Já em 1853, há o registro (PERLIN, 2003) de que, na França, atas de reunião de surdos em Paris indicavam sua mobilização. Este é um aspecto que marca a "História Cultural", fase em que a história é contada pela perspectiva do surdo, em que procura levar a voz dos surdos, representadas pelas associações, federações, movimentos sociais, "através de relatos, depoimentos, fatos vivenciados e observações de povo surdo, misturando-se em um emaranhado de acontecimentos e ações" (STROBEL, 2009, p. 31).

Contudo, foi somente a partir da década de 1960 que a filosofia oralista, imposta em 1880, sofreu fortes críticas. Estudos com base na Linguística, dirigidos por Stokoe, na Universidade de Gallaudet, demonstraram que a língua de sinais era uma língua natural (DUARTE, 2013, p. 1724). Nesta mesma época, muda-se para "surdo", a denominação que se usava de "deficiente auditivo".

Se particularizarmos a história dos surdos em relação ao Brasil, podemos indicar os anos de 1855, quando dom Pedro II traz Huet, professor surdo e seguidor do método do uso de língua de sinais, a fim de trabalhar com os surdos no Brasil; e o de 1857, quando em setembro, o Instituto Nacional de Educação de Surdos-mudos foi fundado, atual Instituto Nacional de Educação dos Surdos (INES). Mesmo o Instituto sendo fundado a partir da valorização da língua de sinais, ele não fica imune à influência das decisões do Congresso de Milão e, por um período, passa também a proibir a língua de sinais em prol do oralismo puro.

Dois grandes marcos na educação de surdo aqui no Brasil são a Lei e o Decreto da Libras (respectivamente, Lei n 10.436 , de 24 de abril de 2002 e Decreto n ${ }^{\circ} 5.626$, de 22 de dezembro de 2005), no entanto, vale frisar que já se passaram 17 e 14 anos que a Lei e o Decreto foram promulgados e, no entanto, ainda precisamos investir em seus cumprimentos porque as mudanças ainda são acanhadas em todos os setores públicos: saúde, educação, meios de comunicação, trabalho e esporte, entre outros.

8 I - The Congress - Considering the incontestable superiority of speech over signs in restoring the deaf-mute to society, and in giving him a more perfect knowledge of language, declares That the Oral method ought to be preferred to that of signs for the education and instruc tion of the deaf and dumb. II - The Congress Considering that the simultaneous use of speech and signs has the disadvantage of injuring speech, lip-reading, and precision of ideas, Declares That the Pure Oral method oughtto be preferred (...). IV - The Congress Considering that the teaching of the speaking-deaf by the Pure Oral method should resemble as much as possible that of those who hear and speak, declares 1 . That the most natural and effectual means by which the speaking-deaf may acquire the knowledge of language is the "intuitive" method, viz., that which consists in setting forth, first by speech, and then by writing, the objects and the facts which are placed before the eyes of the pupils (...).

9 Texto em Word, disponibilizado na internet, extraído, pela própria Sá, do livro: Cultura, poder e educação de surdos. São Paulo: Paulinas, 2006. http://bit.ly/2RaR2k3. Acesso em 04/04/19. 
Mesmo em 2019, a comunidade surda ainda clama por educação bilíngue como o modelo de sua educação, ou seja, o letramento acontecer primeiro em sua língua materna e só depois a aprendizagem escrita da língua oral de seu país. A exemplo dessa situação, relatamos resumidamente a "fala" do Prof. Geraldo Ferreira Filho (ex-aluno no curso de Letras Libras da Universidade Federal de Sergipe, atualmente professor substituto nessa instituição) na audiência pública na Assembleia Legislativa de Sergipe, aos dez dias do mês de maio, cuja temática foi "Escola bilíngue de surdos: do direito à prática".

É uma oportunidade única debater a temática. Minha intérprete é mulher. Vou debater o processo histórico vivenciado por mim, por ser aluno surdo... O principal instrumento capacidade de acesso para qualquer indivíduo é a língua, no caso dos surdos é a língua brasileira de sinais....Tinha professor ensinando libras, mas faltava o sentimento e o conceito...naão tinha uma identidade...eu via o professor ouvinte e achava que o surdo não era capaz, não tinha um modelo, não tinha nenhum surdo como referência, eu achava que não era capaz... em 2003 - veio uma surda de Maceió para estudar no IPAESE, ela já tinha fluência em libras ...pensei ela é ouvinte ....Ela sinalizava bem, ela é ouvinte, os surdos não são capazes de fazer isso, Eu mesmo enquanto surdo tinha esta discurso...Eu perguntei ...você é surda? Sim, você é surda?...você é surda?

Não imaginava que isto era possível, você é capaz?....eu, com 16 anos, só conhecia 3 palavras; pai, mãe e água. ..A partir daí que foi meu despertar. Vi que era possível...a prova está ai, surdos que estudam na UFS, isto é uma satisfação...Importante ter uma identidade surda, ter isso como modelo... Se não tem o modelo surdo, não é uma escola bilíngue (foi aplaudido neste parte)....A família ouvinte, é de forma natural que acontece aquisição natural da língua...uma língua materna de forma natural, vai para a escola ...o que vai obter na escola é o significado, o aprofundamento....Associar os conhecimentos de mundo com os espaços sociais que frequentou. E o indivíduo surdo? A família é ouvinte, 95\% são filhos de pais ouvintes que não sabem libras, o indivíduo surdo nasce e não tem o contato com a língua, não tem o som, não tem esta referência...vai ter aquisição pela visão... Este individuo inserido no espaço inclusivo ...como ele vai começar a entender se não tinha anteriormente as informações que deveria ter nos espaços sociais...não vivenciou, como se resolve? Acesso tarde, gera problema social... Meu mundo era obscuro, com imensas barreiras, não que eu não visualizasse...Com 16 anos...a minha lanterna foi a Língua Brasileira de Sinais...Em contato com outros surdos, as histórias são semelhantes...A Língua Portuguesa é como uma língua estrangeira... na escola bilíngue língua Portuguesa se dar como ensino de língua estrangeira....Se o indivíduo não tiver a base linguística vai ter barreira.....Minha preocupação com esta temática....Pela visão os surdos absorvem as informações (FERREIRA FILHO). ${ }^{10}$

O que se observa é que há quase duas décadas do século XXI, histórias como a acima relatada ocorreram com vários surdos e continuam acontecendo. Como defende Touraine: "cuando hablo del sujeto, es decir, de la constituición del individuo como actor, resulta imposible separar el individduo de sua situacion social. E o autor continua: "El sujeito sólo existe como movimento social, como posición a la lógica del orden" (TOURAINE, 2000, p. 232).

Foi com este posicionamento que os surdos se fortaleceram através de movimentos sociais em prol de sua causa, em prol de sua voz contra as vozes de ouvintes experts em educação e dos ouvintes que procuravam "normalizar" os surdos. No pensamento de Touraine, um movimento

10 Arquivo pessoal da pesquisadora que esteve presente na audiência pública. Usaremos uma mescla de discurso direto e indireto Fonte da divulgação do evento: http://bit.ly/36KZb5i. Acesso em 04/06/19. 
social é tanto um conflito social quanto um projeto cultural. Isto porque um movimento social busca a vitória diante de um adversário social (conflito social), quanto deseja a realização de valores culturais (projeto cultural).

\section{Abordagem Sociológica e Comunicacional do Discurso: contribuições PARA ESTUDOS EM RELAÇÕES DE PODER E MUDANÇA SOCIAL}

A corrente da ACD que seguimos é a Abordagem Sociológica e Comunicacional do Discurso - ASCD ${ }^{11}$ (BESSA, 2016; PEDROSA, 2018). Esta corrente brasileira contribui com os estudos críticos, dialogando com a Sociologia para a Mudança Social (BAJOIT, 2006), a Sociologia Aplicada a Mudança Social (SACO, 2006); Comunicação para a Mudança Social (GUMUCIO-DAGRON, 2008); Estudos Culturais e, quanto à tessitura textual, trabalha com a Linguística Sistêmico-Funcional (HALLIDAY, 2004).

Neste artigo, priorizaremos a Sociologia para a Mudança Social com base no sociólogo belga Bajoit. Relações de poder e mudança social serão os recortes aplicados para análise. Vejamos o parecer de Meyer sobre o diálogo com a Sociologia: "A ACD parece achar-se mais próximas das perspectivas sociológicas e sociopsicológicas, embora estas interfaces não se encontrem bem definidas em todas as partes" (MEYER, 2003, p.38).

Entre os objetivos de pesquisa em ASCD, que podemos listar com base na Sociologia para a Mudança Social, estão: identificar os tipos de mudanças sociais e culturais que o objeto de investigação sofreu historicamente; estabelecer diferenças entre as forças de coerção dos poderes; investir em estudos identitários, articulando as identidades sociais e individuais.

Tomando por base Bajoit, listamos o que o sociólogo considera como sendo a modificação de um estado das relações sociais, o que considera uma mudança social:

1. mudança das coações pelas quais se resolvem os problemas vitais da vida comum;

2. mudança dos princípios de sentido invocados para legitimar estas coações; 3 . mudança das identidades coletivas que resultam da prática das relações sociais; 4. mudança das lógicas de gestão de si, pelas quais os indivíduos resolvem as tensões que atravessam essas identidades coletivas e constroem suas identidades pessoais; 5 . mudança das lógicas de ação nas quais se comprometem, individualmente ou coletivamente (BAJOIT, 2008, p. 252).

O autor defende que os intercâmbios sociais cooperam para reproduzir e/ou para transformar as estruturas que constituem as relações sociais. Os intercâmbios classificam-se em: cooperativos, conflitivos, competitivos e contraditórios (BAJOIT, 2008).

Os conflitivos têm o papel de inibir a reprodução das relações sociais para que estas se renovem. Isto é gerado por tensões entre grupos sociais, considerando que o grupo que tem o domínio buscar alimentar estas relações pelo (abuso) de poder. Nos intercâmbios competitivos, está em jogo a escolha do melhor, do mais forte, é a busca por vencer e deslegitimar ações do "inimigo". Os intercâmbios contraditórios apresentam a mesma lógica dos intercâmbios competitivos, entretanto, enquanto os competitivos seguem regras, os contraditórios são ações alheatórias. Quanto ao tipo de intercâmbio contraditório, Bajoit chama atenção para a ameaça de morte social (ou mesmo

11 Cf. Site www.ascd.com.br. 
física) dos atores sociais vulneráveis, por estarem desprovidos de "ferramentas" de luta para entrar no jogo.

Em princípios, as sociedades precisam de equilíbrio na existência desses intercâmbios. As mudanças sociais e culturais são necessárias, porém, na maioria das vezes, são resultantes de processos tensos, de arenas discursivas e práticas sociais que se instauram num jogo de poder e luta reivindicatória.

Além dos intercâmbios (mudanças mais pontuais), Bajoit indica uma classificação para as vias da mudança social mais amplas. $\mathrm{O}$ autor divide as mudanças socioculturais em dois grandes campos: a mutação e a ruptura. $\mathrm{Na}$ mutação, enquadram-se a evolução e a reforma; na ruptura, fazem parte a revolta e a revolução. A evolução é um tipo de mudança gerada a partir dos intercâmbios cooperativos e competitivos entre membros de categorias sociais não organizadas. Já Por outro lado a reforma é um tipo de mudança que está pautado no intercâmbio cooperativo, é resultante de decisão coletiva, tendo por base a negociação entre atores sociais organizados em busca de um bem comum.

No enquadre da ruptura, a revolta é um tipo de mudança que é resultante de uma mobilização espontânea dos membros de uma categoria social em intercâmbios conflitivos e contraditórios. Sua característica principal é a ausência de organização, de solidariedade entre seus participantes. A revolução é uma espécie de mudança regulada nos intercâmbios conflitivos e contraditórios. A diferença em relação à revolta é que a revolução é embasada em ação solidária e organizada, aspirando uma inovação social.

Em resumo, segundo Bajoit, as mudanças sociais e culturais devem ser explicadas avaliando-se, na gestão das tensões sociais, o papel dos atores individuais e coletivos. Esses atores tornam-se responsáveis pelos significados, que se instauram em sua relação com o outro, ao constituírem suas subjetividades.

Outro aspecto na discussão é a relação de poder estabelecido socialmente, principalmente, na polarização social. Este é também um outros foco de estudos discursivos, Wodak (2003, p. 31) já afirmava que "a ACD se interessa pelos modos em que se utilizam as formas linguísticas em diversas expressões e manipulações do poder", Como para nós ainda é necessário investir numa análise sob esta perspectiva, então a Abordagem Sociológica e Comunicacional do Discurso buscou ampliá-la.

Como a linguagem evoca poder, logo as relações de poder são discursivas. Contudo, o poder não existe na linguagem por si, argumenta Wodak, isto ocorrerá sempre via sujeito. Podemos acrescentar ainda acerca desse aspecto que o poder não seria identificável apenas em suas formas gramaticais nos textos \discursos, porém, mormente, em como os indivíduos, ao fazer uso do texto/discurso, exercem domínio sobre as outras pessoas.

Deste modo, a linguagem é uma forma de dominação e de força social, legitimando as relações de poder que foram estabelecidas institucionalmente. Por isso que os analistas críticos desenvolvem um tipo de análise que objetiva desvelar em como os discursos podem estar carregados da dimensão do poder, do controle social.

O quadro teórico da ASCD assume os diferentes tipos de poder os quais são referendados em Bajoit. Para esse sociólogo, as coletividades, para sobreviverem no tempo e no espaço, preci- 
sam achar soluções para seus problemas vitais, quais sejam, administrar: a produção de riquezas, a ordem interna, a socialização de seus membros, o consenso e a solidariedade e suas relações com outras coletividades. A partir desses tipos de socializações, surgem diferentes tipos de repressão/ coerção: domínio, poder, autoridade, influência e hegemonia. Recontextualizando para a ACSD, ao considerarmos o discurso, utilizaremos os termos poder-domínio, poder-Estado, poder-autoridade, poder-influência, e poder-hegemonia.

O poder-domínio refere-se à produção e o emprego social das riquezas de uma coletividade. Como as riquezas geralmente são insuficientes, geram-se conflitos entre os atores sociais: gestores e produtores. O poder-Estado refere-se ao tipo de regime político, envolvendo: legislar; julgar; reprimir e governar. Os atores sociais são: as elites estatais e os cidadãos. O poder-autoridade refere-se ao modelo que dá conta da socialização dos membros de uma coletividade, e tem por base as regras adotadas por eles: prescrever e incutir as regras, garantir a autoridade da hierarquia, avaliar as condutas dos dirigidos e castigar o desvio social. Os atores sociais são: as hierarquias e os dirigidos. O poder-influência refere-se à relação social em que dão conta do estabelecimento, negociação e se garantia dos compromissos, também da existência entre os diferentes grupos. Os atores sociais são: os grupos instalados e os grupos minoritários. O poder-hegemonia refere-se ao modo de administrar, nos âmbitos regional e internacional, as relações entre as coletividades. Os atores são: as coletividades hegemônicas e as coletividades dependentes.

\section{Por uma metodologia para A ANÁlise sócio discursiva}

Por trabalharmos com o discurso, utilizaremos uma metodologia aplicada, qualitativa e sob a perspectiva interpretativista. O uso da análise linguística será através da Linguística Sistêmico-Funcional (LSF) / Gramática Sistêmico-Funcional (GSF) que respaldará as interpretações, considerando que as análises em ACD devem atender ao linguístico e ao socio-discursivo.

Os corpora, a serem analisados, foram coletados de três documentos, dos quais extrairemos recortes que ajudarão a atingir o objetivo pretendido. O primeiro documento é a conhecida Lei da Libras. Essa Lei foi promulgada em 2002 (Lei no 10.436, de 24 de abril de 2002) e reconhece a Libras como meio de comunicação do povo surdo. O Decreto da Libras (Decreto no 5.626, de 22 de dezembro de 2005), "Regulamenta a Lei no 10.436, de 24 de abril de 2002, que dispõe sobre a Língua Brasileira de Sinais - Libras, e o art. 18 da Lei n ${ }^{\circ}$ 10.098, de 19 de dezembro de 2000". Por último, a Carta reivindicativa de sete doutores surdos nas áreas de Educação e Linguística sobre a educação bilíngue para os surdos (Carta Aberta dos Doutores Surdos ao Ministro Mercadante, 2012).

Para atender as especificidades deste trabalho, traçaremos os seguintes passos nas análises: I) Exame das formas de mudança social que os objetos de investigação (Lei, Decreto e Carta), no nosso caso, o discurso sobre educação de surdos, sofreram historicamente; II) Estabelecimento das diferentes formas de força de coerção manifestas no discurso, ou seja, as questões relativas ao poder; III) Aplicação da Linguística Sistêmico-Funcional/Gramática Sistêmico-Funcional, representada pela Metafunção interpessoal, à materialidade linguística.

A contextualização teórica e os passos que sugerimos seguir visam atender ao objetivo deste artigo: analisar, linguístico-sociodiscursimente, trechos de documentos que apontam para as reivindicações dos surdos quanto a seu direito por uma educação bilíngue. 


\section{Polarização de vozes: os caminhos para a educação de surdos no Brasil}

Historicamente, no Brasil, entre as décadas de 1970 e 1990, há mobilizações sociais do Povo Surdo que continuam até o presente, como a Audiência Pública que relatamos acima (Aracaju, SE, Brasil, 10/05/2019) e tem como objetivo reivindicar seus direitos. E em conformidade com dados da autora Garé (2016), diálogos com o Estado começaram a partir de 1990. Isso responde às lutas de solidariedade, baseada na ideia de equidade e não mais de igualdade (VAN DIJK, 2008; BAJOIT, 2006; HONNETH, 2003).

A seguir, os fragmentos a serem analisados. Explicamos o uso da Lei e do Decreto da Libras como corpora para análise porque defendemos que eles são uma resposta governamental às reivindicações dos surdos em movimentos sociais, logo, nestes documentos está a voz do surdo.
a- Lei da Libras - Lei $n^{\circ} 10.436$, de 24 de abril de 2002
Art. 4o $\mathrm{O}$ sistema educacional federal e os sistemas educacionais estaduais, municipais e do Distrito Federal devem garantir a inclusão nos cursos de formação de Educação Es- pecial, de Fonoaudiologia e de Magistério, em seus níveis médio e superior, do ensino da Língua Brasileira de Sinais - Libras, como parte integrante dos Parâmetros Curriculares Nacionais - PCNs, conforme legislação vigente.
Parágrafo único. A Língua Brasileira de Sinais - Libras não poderá substituir a modalidade escrita da língua portuguesa.

A Lei estabelece a obrigatoriedade da língua de sinais nos cursos de Fonoaudiologia e de Magistério. Ao poder-Estado, cabe-lhe legislar, e aos cidadãos, cabe-lhes seguir a Lei. Este foi um grande passo reverso, considerando que historicamente os surdos eram obrigados a estudar a língua dos ouvintes. Nos intercâmbios conflitivos, há a presença de grupos oprimidos na arena social a fim de gerar mudanças socioculturais ao buscar maior compartilhamento de direitos.

Reforçamos que se com um semestre de Libras não ocorre a bilinguilidade dos ouvintes, pois 60 horas de uma Língua, ainda dividida entre prática e teoria, não capacita nenhum estudante a utilizá-la fluentemente; no entanto, pelo menos, ocorre maior sensibilização e conscientização dos futuros profissionais que trabalharão com a linguagem, ou mesmo, que venha a atender a surdos.

O parágrafo único deste artigo, configura-se como obrigatoriedade do bilinguismo surdo. Eles passam a ter direito à sua língua, contudo, esta não substitui a língua majoritária. É a voz do poder-Estado, pois este tem o domínio do legislar, de poder decidir sobre o permitido e o proibido com base nas leis estabelecidas (BAJOIT, 2008).

Neste contexto, trazemos ainda o que diz Bajoit (2006, p. 41): “É preciso gerir o consenso e a solidariedade entre as categorias sociais com diferentes interesses, caso contrário a coletividade será destruída por desigualdade insuportável". Ao que podemos comprovar, a Lei da Libras foi uma conquista do Povo Surdo como resultado das mobilizações e diálogo com o Estado (GARÉ, 2016).

b- Decreto de la Libras (2005) - Decreto no 5.626, de 22 de dezembro de 2005.

Capítulo IV- Do uso e da difusão da Libras e da Língua Portuguesa para o acesso das pessoas surdas à educação

Art. 14. As instituições federais de ensino devem garantir, obrigatoriamente, às pessoas surdas acesso à comunicação, à informação e à educação nos processos seletivos, nas atividades e nos conteúdos curriculares desenvolvidos em todos os níveis, etapas e modalidades de educação, desde a educação infantil até à superior. 
$\int 1^{\circ}$ Para garantir o atendimento educacional especializado e o acesso previsto no caput, as instituições federais de ensino devem:

(...)

II - ofertar, obrigatoriamente, desde a educação infantil, o ensino da Libras e também da Língua Portuguesa, como segunda língua para alunos surdos;

III - prover as escolas com:

(...)

c) professor para o ensino de Língua Portuguesa como segunda língua para pessoas surdas; e

d) professor regente de classe com conhecimento acerca da singularidade lingüística manifestada pelos alunos surdos;

(...)

VI - adotar mecanismos de avaliação coerentes com aprendizado de segunda língua, na correção das provas escritas, valorizando o aspecto semântico e reconhecendo a singularidade lingüística manifestada no aspecto formal da Língua Portuguesa;

(...)

Após três anos da Lei da Libras, foi promulgado o Decreto da Libras a fim de regulamentar esta Lei. A difusão da Libras tem o objetivo de oferecer ao Povo Surdo o acesso à educação. Para isto era necessário que o País contasse com profissionais capacitados a fim de formar outros, e que também atendessem aos surdos.

Em agosto de 2001, a FENEIS-RJ (Federação Nacional de Educação e Integração de Surdos), junto ao Programa Nacional de Apoio à Educação do Surdo do MEC, tinha capacitado 80 Surdos no Brasil, a fim de estes fossem Instrutores de LIBRAS, além dessa ação, "desenvolveu métodos de ensino e materiais didáticos que ofereceram aos alunos Surdos uma educação de qualidade" (MONTEIRO, 2006, p. 300).

Logo em seguida, setembro deste mesmo ano, outra ação tinha o mesmo direcionamento, ocorreu a capacitação de 54 Professores/Intérpretes, cujo desafio era atuarem nas escolas inclusivas. Estas foram, sem dúvidas, ações basilares que prepararam o terreno para os dois marcos na História dos Surdos: a promulgação da lei da Libras ( N $^{\circ} 10.436$ de 24 de abril de 2002), documento em que há reconhecimento da Libras como língua da comunidade surda; e em 2005, ocorreu a Regulamentação desta através do Decreto n 5626 do dia 22 de dezembro de 2005. Era a "voz" do surdo sendo legitimada através de documentos oficiais nacionais. Mas, na prática, não vamos nos enganar, pois 134 instrutores e professores não correspondem a uma demanda aceitável para a realidade dos Surdos no Brasil. Com nossa dimensão continental, já chegamos a mais de 209 milhões de habitantes, e de acordo o censo do IBGE (Instituto Brasileiro de Geografia e Estatística), 9,7 milhões de brasileiros têm deficiência auditiva. Destes, 2.147.366 milhões tem deficiência auditiva severa $^{12}$. Nesse cálculo, quase um milhão são jovens até 19 anos ${ }^{13}$; logo, o número de capacitados, na época, não atendia a demanda.

Em 2006, a UFSC (Universidade Federal de Santa Catarina) abre cursos de Letras Libras para licenciar surdos e bacharelar ouvintes como intérpretes de Libras. Em 2010, é regulamentada a profissão de Tradutor Intérprete da Libras através da Lei n ${ }^{0} 12.319$, de $1^{\circ}$ de setembro ${ }^{14}$. No ano 12 Perda entre 70 e 90 decibéis $(\mathrm{dB})$.

13 Cf. http:/ / bit.ly/2TgXSY4. Acesso em 20\09\17, as 17h35 por Portal Brasil publicado: 28/09/2016 15h09 última modificação: 28/09/2016 18h39

14 Cf. http://bit.ly/35Hk7sE. Acesso em 23 jul. 2019. 
atual, temos, no âmbito de mudanças socioculturais para o Povo Surdo, o Decreto $\mathrm{n}^{\circ}$ 9.465, de 2 de janeiro de 2019. No capítulo II desse Decreto encontramos a estrutura organizacional do MEC, que, em seu art. $2^{\circ}$, apresenta a estrutura do Ministério da Educação, com a Diretoria de Políticas de Educação Bilíngue de Surdos (Art. 35) e o Instituto Nacional de Educação de Surdos (Art. 38) e suas competências em relação à educação bilíngue dos Surdos, e a valorização de sua língua.

$\mathrm{Na}$ verdade, o Brasil está bem assessorado de Leis e Decretos; porém, pouca efetivação de políticas públicas para os Surdos. Mesmo diante deste fato, justamente, mão vamos olvidar alguns avanços bem relevantes.

Outra mudança em destaque, foi que em 2017, o Exame Nacional do Ensino Médio (Enem) apresentou a versão em Libras e também disponibilizou o tradutor-intérprete. Esta versão foi selecionada por 1.635 participantes com surdez ou deficiência auditiva, e 1.357 candidatos também escolheram o tradutor-intérprete. ${ }^{15}$

Mais ações efetivas podem ser respaldadas através do PROLIBRAS (Programa Nacional para a Certificação de Proficiência no Uso e Ensino da Língua Brasileira de Sinais - Libras e para a Certificação de Proficiência em Tradução e Interpretação da Libras/Língua Portuguesa), este certificou, entre 2006 - 2010, 6.101 profissionais. Até 2009, a UFSC tinha certificado 5.128. A Portaria MEC, $n^{\circ}$ 20/2010, determinou que o PROLIBRAS ficaria sob a responsabilidade do Instituto Nacional de Educação de Surdos - INES. ${ }^{16}$ "É um número baixo se considerarmos que, de acordo com o IBGE, aproximadamente 9,7 milhões de brasileiros possuem alguma deficiência auditiva (o equivalente a 5,1\% da população)" ${ }^{\prime 17}$, reforça, também esta relação entre demanda e oferta, o portal da Faculdade Eficaz.

Vejamos o último exemplo para análise:

c- Carta reivindicativa de doctores sordos sobre la educación bilingüe (2012).

Várias pesquisas mostram que os surdos melhor incluídos socialmente são os que estudam nas Escolas Bilíngues, que têm a Língua de Sinais brasileira, sua língua materna, como primeira língua de convívio e instrução, possibilitando o desenvolvimento da competência em Língua Portuguesa escrita, como segunda língua para leitura, convivência social e aprendizado (...). Senhor Ministro, queremos dizer que nossa reivindicação por Escolas Bilíngues, tal como acima definimos, se apoia na Convenção (particularmente no Art. $24^{\circ}$, inciso 3, e Art. $30^{\circ}$, inciso 4, letras "b" e "c") e na IDA (International Disability Alliance), órgão da sociedade civil internacional, que aglutina as entidades internacionais dos diversos segmentos das pessoas com deficiência, tendo sido a principal articuladora social responsável pela realização da Convenção Internacional das Pessoas com Deficiência, no âmbito das Nações Unidas (e que, por isso mesmo, continua a atuar junto à ONU no acompanhamento e fiscalização da implementação da Convenção (...). Rogamos-lhe, Senhor Ministro, que GARANTA AS ESCOLAS BILÍNGUES, COM INSTRUÇÃO EM LIBRAS E EM PORTUGUÊS ESCRITO, NAS DIRETRIZES EDUCACIONAIS DO MEC e que REFORCE a importância de sua inclusão no PNE. Essas escolas respeitam a especificidade linguístico-cultural das crianças e jovens surdos e sua viabilidade representa a garantia ao direito que os surdos têm a uma educação bilíngue específica, a qual permite o convívio entre seus pares (em ambientes linguisticamente adequados) (CARTA, p. 01, 06-07).

15 Cf. http://bit.ly/2uKuTSl. Acesso em 23 jul.2019.

16 Cf. http://bit.ly/36OpZSn. Acesso em 23 de jun.2019.

17 Cf. http://bit.ly/36PGNse. Acesso em 23 de jun. 2019. 
Anteriormente apresentamos fragmentos de dois textos legais $(2002,2005)$, por último, fragmentos de uma Carta enviada ao Ministro de Educação, em 2012, pelos primeiros sete doutores do Brasil nas áreas de Educação e Linguística. Essa carta representa a voz de surdos que já alcançaram o grau máximo da escolarização, que se apresentam como protagonistas ou atores de sua história em uma clara resistência às políticas educacionais do Ministério de Educação, que implicitamente não está demonstrando esforços para que a educação bilíngue dos surdos ocorra: "Rogamos-lhe, Senhor Ministro, que GARANTA AS ESCOLAS BILÍNGUES, COM INSTRUÇÃO EM LIBRAS E EM PORTUGUÊS ESCRITO, NAS DIRETRIZES EDUCACIONAIS DO MEC e que REFORCE a importância de sua inclusão no PNE”.

Essa carta foi escrita após 10 anos da Lei da Libras, numa demonstração de que o movimento surdo necessitava continuar, pois sua educação e suas necessidades estavam longe de atingir o ideal. Cidadãos deveriam ter seus direitos respeitados, ainda mais quando estes direitos são outorgados por Leis Federais. Quanto a essa questão, Ottone (2011, p. 60-61), explica-nos:

\section{La aspiracion a la igualdad social, tal como la entendemos hoy, es um fenómeno relativamente reciente en la bistória bumana. Adquiere certa centralidade teórica y política recién em el siglo XIX, impulsada por las ideas socialistas, y se expande a través de los avatares del siglo XX, perído en el que fue objeto de lectura e interpretaciones muy distintas e incluso contrapuestas.}

A igualdade social, ou melhor, a equidade entre os cidadãos deveria ser uma busca de todas as sociedades, não só uma busca, mas uma meta, um compromisso. Contudo, esta situação não é tão pacífica como deveria ser. Os grupos vulneráveis, quase sempre invisíveis, precisam lutar por e conquistar seus direitos, fazendo sua voz polemizar com a voz já estabelecida dos que detêm o poder; seja o poder-autoridade, aquele que se refere ao modelo que orienta a socialização dos membros de uma coletividade, e tem por base as regras por eles adotadas ou o poder-influência que se refere à relação social em que há o estabelecimento, a negociação e a garantia dos compromissos entre os diferentes grupos.

Ainda segundo Ottone, a concepção de igualdade social se originou com base no conceito de cidadania, oriundas da Revolução francesa, do Estado moderno e da Revolução industrial, contudo não foi sem lutas sociais, sem revoluções, sem reformas, sem compromissos "que la bumanidade fue dando pasos progressivos - tanto em los hechos como em los conceptos - para concebir la igualdad social como uma aspiración legítima y como uma meta deseable, al menos expresando una tendência" (Ottone, 2011, p. 62).

A Carta dos doutores surdos é um exemplo dessa busca por equidade social. Sete doutores pioneiros em Educação e Linguística expõem, com base em pesquisas e documentos internacionais como Convenções e Alianças, que o que estão reivindicando tem bases cientificas, sociais e humanísticas.

Quanto ao aspecto linguístico dos textos, ressaltaremos, com base na Linguística Sistêmico-Funcional (LSF), principalmente, a tessitura textual do último exemplo, considerando que os outros dois primeiros atendem a uma tessitura mais homogênea com características próprias dos textos legais.

A LSF traz para o cenário dos estudos da linguagem uma visão de língua em uso - funcionalismo (HALLIDAY, 2004). Ghio e Fernandez destacam este caráter do estudo da linguagem em seu contexto social. Afirmam os autores, com base em Halliday, "que una de las principales tareas 
de la linguística es explicar el papel que la lengua desempeña en la cultura y en el mundo social' (GHIO, FERNANDEZ, 2005, p. 05). Assim, entendemos que a linguagem utilizada em documentos legais atende à demanda linguística cultural e social para estes tipos de gêneros textuais, a exemplos dos fragmentos (metafunção textual): "O sistema educacional federal, e os sistemas... devem garantir a inclusão" e "Libras não poderá substituir a modalidade escrita da língua portuguesa" da Lei da Libras (2002); e "As instituições federais de ensino devem garantir, obrigatoriamente, às pessoas surdas acesso à comunicação", "Para garantir o atendimento educacional especializado e o acesso previsto no caput, as instituições federais de ensino devem...", "prover", “ofertar", "adotar" do decreto da Libras (2005).

Verificamos, no entanto, que o $3^{\circ}$ exemplo apresenta uma tessitura textual bem diversa. $\mathrm{O}$ texto é dialógico, enfatizando a Metafunção interpessoal. A LSF defende que o aspecto social é inseparável do sistema linguístico. Logo é essencial demonstrar a relação dialética entre usos sociais e o sistema da língua. Para isso, propõe o termo Metafunção (ampliando o termo função) "para referirse a essas funciones más abstractas que son uma propriedade inherent a todas las lenguas" (GHIO; FERNANDES, 2005, p. 15).

A Metafunção interpessoal, a que fizemos referência como a característica forte no texto dos sete doutores surdos, diz respeito à expressão de nossa participação em uma situação comunicativa, envolve as regras que impomos ou assumimos, nossas atitudes, juízos, sentimentos, desejos, crenças, etc, (GHIO; FERNANDES, 2005).

Certificamos o uso efetivo, entre outros: da interpelação dos doutores com o Ministro da Educação do Brasil na época - "Senhor Ministro" / "Rogamos-lhe, Senhor Ministro"; dos desejos - "queremos dizer que nossa reivindicação por Escolas Bilíngues, tal como acima definimos"; das crenças - "Várias pesquisas mostram que os surdos melhor incluídos socialmente são os que estudam nas Escolas Bilíngues..." / "Essas escolas respeitam a especificidade linguístico-cultural das crianças e jovens surdos e sua viabilidade representa a garantia ao direito que os surdos têm a uma educação bilíngue específica, a qual permite o convívio entre seus pares".

Concluindo a análise, trazemos Honneth (2003, p. 261-277) que, através de seu livro - Luta por reconhecimento: a gramática moral dos conflitos sociais, enfatiza que o conflito começa quando o coletivo tem sentimento de injustiça vivenciados por este mesmo coletivo seja através da denegação de reconhecimento jurídico ou reconhecimento social. Ambos vivenciados pelos surdos. No dizer do autor "o reconhecimento jurídico contém em si um potencial moral capaz de ser desdobrado através de lutas sociais" porque a "auto-realizacão depende do pressuposto social da autonomia juridicamente assegurada, visto que só com base nela cada sujeito é capaz de se conceber como uma pessoa".

Pelo que acompanhamos, mesmo o reconhecimento das necessidades do Povo Surdo assegurado juridicamente (inclusão) não foram efetivadas na prática social (exclusão).

\section{(IN)CONCLUSÃO}

Resultados das análises apontam que os textos nos oferecem condições de recuperar a memória discursiva e sócio- histórica da comunidade surda e sua luta por educação bilíngue, não só num impasse de "polifonia social" divergente entre surdos e ouvintes; mas também, em outras ocasiões, numa polifonia convergente de vozes de surdos e de ouvintes. 
A busca por equidade na educação dos Surdos deveria ser uma questão não só dos Surdos e de seus familiares ouvintes; mas de toda uma sociedade. Otonne (2011, p. 65), por exemplo, defende que "La noción de igualdad social, que bá hecho um largo recorrido par alegitimarse, deberia ser hoy um valor compartido socialmente no solo desde um punto de vista ético, sino también por razones de eficiência..." Assim, se as questões éticas não forem suficientes para nós agirmos de forma solidária com os surdos; há ainda que considerarmos as razões de eficiência. Contudo como humanos, apostamos na ética. E como acadêmica, que trabalha com ACD, apostamos também na solidariedade e na cooperação.

A reflexão acerca do papel dos acadêmicos na sociedade e na polis transforma-se em uma parte inerente da tarefa proposta pela análise do discurso. Isso talvez signifique, entre outras coisas, que os analistas do discurso orientam suas pesquisas em solidariedade e cooperação com os grupos dominados (VAN DIJK, 2008, p. 114, itálico do autor, negrito nosso).

\section{REFERÊNCIAS}

BAJOIT, G. El cambio social, análisis sociológico del cambio social y cultural en las sociedades contemporáneas. Madrid: Siglo, [2003]2008.

BAJOIT, G. Tudo muda: proposta teórica e análise da mudança sociocultural nas sociedades ocidentais contemporâneas. Rio Grande do Sul, Brasil: Editora UNIJUÍ, 2006.

BAUMAN, Z. Modernidade líquida. Buenos Aires: Fondo de Cultura Econômica, 2009.

BRASIL. Lei n. 12.319, de 01 de setembro de 2010. Brasília. Disponível em: http://bit.ly/36Lm4FK. Acesso em: 06/01/2019.

BRASIL. Decreto n. 5.626, de 22 de dezembro de 2005. Regulamenta a Lei n. 10.436, de 24 de abril de 2002, que dispõe sobre a Língua Brasileira de Sinais - Libras, e o art. 18 da Lei n. 10.098, de 19 de dezembro de 2000. Disponível em: http://bit.ly/36PH2Ua. Acesso em: 10/01/2018.

BRASIL. Lei n. 10.436 de 24/04/2002. Dispõe sobre a Língua Brasileira de Sinais - LIBRAS - e dá outras providências. Disponível em: http://bit.ly/3ad4I70. Acesso em: 15/01/2014.

CARTA. Carta aberta dos doutores surdos ao ministro Mercadante. Disponível em: http://bit.ly/35MMO7A. Acesso em: 30/05/ 2019.

DUARTE, S. B. R. [et al]. Aspectos históricos e socioculturais da população surda. In: História, Ciências, Saúde. Manguinhos, Rio de Janeiro, v. 20, n. 4, out.-dez. 2013, p.1713-1734.

FAIRCLOUGH, N. Discurso e mudança social. Brasília: Editora Universidade de Brasília, [2001] 2008.

GARÉ, R. M. R. Educação formal x educação não formal: diferentes práticas de ensino e a construção de identidades surdas. São Paulo: Gregory, 2016.

GHIO, E.; FERNÁNDEZ, M. D. Manual de linguística sistémico funcional: el enfoque de M. A. K. Halliday \& R. Hasan - aplicaciones a la lengua española. Santa Fé Universidad Nacional del Litoral, 2005.

GUMUCIO-DAGron, A.; TUFTE, T. (Comp.). Antología de Comunicación para el Cambio Social: Lecturas históricas y contemporáneas. La Paz, Bolivia: Plural Editores, 2008.

HALLIDAY, M. A. K. An introduction to Functional Grammar [Revisão de Christian M. I. M. Matthiessen]. 3. ed. London: Edward Arnold, 2004.

HONNETH, A. Luta por reconhecimento: a gramática moral dos conflitos sociais. São Paulo: Editora 34, 2009.

KINSEY, A. A. Report of the proceedings of the International Congress of the Education of the Deaf held at Milan. September 6th-11th. London: W.H. Allen \& Co, 1880.

MAGALHÃES, I.; MARTINS, A. R.; RESENDE, V. M. Análise de discurso crítica: um método de pesquisa qualitativa. Brasília: Editora UnB, 2016.

MONTEIRO, M. S. História dos movimentos dos surdos e o reconhecimento da Libras no Brasil. In: ETD 
- Educação. Temática Digital, v. 7, n. 2, 2006, p. 295-305. Disponível em: http://bit.ly/2G6yts4. Acesso em 13/05/2019.

ORTÚZAR, P. Elpoder del poder: repensar la autoridade en tiempos de crisis. Santiago: Tajamar Editores, 2016.

OTTONE, E. Gobernar la globalización. Santiago de Chile: Ediciones Universidad Diego Portales, 2011.

PEDROSA, C. E. F. Análise crítica do discurso e a proposta da corrente nacional: da abordagem às primeiras pesquisas. In: KALLARRARI, C.; BESSA, D.; PEREIRA, A. S. Estudos linguísticos e formação docente. São Paulo: Pontes, 2016, p. 69-100.

PEDROSA, C. E. F. Análise de Discurso Crítica: do linguístico ao social no gênero midiático. Aracaju: EdUFS, 2008.

PERLIN, G. O ser e o estar sendo surdos: alteridades, diferenças e identidade. Tese de Doutorado, Programa de Pós-Graduação em Educação da UFRS, Rio Grande do Sul, 2003.

ROCHELE, E. L. Le Congrés de Milan pour l'amélioration du sort des sourds- muets; rapport adresse a M. Eugène Pereire. Paris: M. Saint-Jorre, 1880.

STROBEL, K. História da Educação de Surdos. Florianópolis: UFSC, 2009.

SÁ, N. L. Os estudos surdos. Texto extraído do livro: Cultura, poder e educação de surdos. São Paulo: Paulinas, 2006 (da autora). Disponível em: http://bit.ly/2uI364S. Acesso em 19/07/19.

TOURAINE, A. Crítica de la modernidade. 2. ed. México: Fondo de Cultura Económica, 2000.

VAN DIJK, T. Discurso e poder. Trad. De Judith Hoffnagel e Karina Falcone. São Paulo: Contexto, 2008. VAN DIJK, T. Principles of critical discourse análisis. In: Discourse \& Society, London: SAGE:, v. 4, n. 2, p. 249283, 1993.

WODAK, R. Critical Discourse Analysis: Challenges and Perspectives. V. 1: Concepts, History, Theory. Los Angeles: Sage, 2013. 